\title{
DEBATE
}

\section{Abortion and the value of the future. A reply to: a defence of the potential future of value theory}

\section{Brown}

The future like ours argument implies no limitation on abortion rights. The author of the argument concedes that on the intended interpretation, abortion is not shown to be impermissible. The alternative self-represented future interpretation also implies a prochoice view.

Correspondence to: Professor M T Brown, University of Wisconsin Marathon County, 518 South 7th Avenue, Wausau, WI USA; mbrown@uwc.edu

Revised version received 16 March 2002

Accepted for publication 18 March 2002 wish to thank Don Marquis for his insightful critiques of my views, and for clarifying his own. Specifically, I am pleased to hear that the potential future of value argument first stated by Marquis in his 1989 essay, Why abortion is immoral, is not intended to imply that abortion is impermissible. ${ }^{1}$ Since this essay has been widely interpreted as an argument against abortion rights, the exchange between Marquis and myself in the Journal of Medical Ethics has served a useful purpose.

My goal throughout this dialogue has been to demonstrate that under no plausible interpretation does the future like ours argument defeat claims to abortion rights. I accept, for the sake of argument, the potential future of value account of the wrongness of killing persons, and I accept, for the sake of argument, that the fetus is a person in this sense, but argue that the right not to be killed does not entail a right to the bodily integrity of another person. Since the right of the fetus not to be killed is biologically intertwined with the bodily integrity of a woman, women are in general entitled to exercise their right to abortion. It is a separate matter whether on any particular occasion a woman ought to exercise this right. Certainly, for most women the perceived nature of the parent/child relationship would weigh heavily in their decision. Apparently, Marquis and I do not disagree on this matter.

Many people find claims to rights to potential futures implausible-potential values are not in general equivalent to actual values-but still feel there is something right about the idea that to kill someone is to deprive them of their future. The harm done to a person by deprivation of their self-represented future may capture this intuition, but on the most plausible interpretation of self-represented future, fetuses cannot be harmed in this way. In A defence of the potential future of value theory, Marquis considers and (rightly) rejects both an interpretation of self-represented futures as momentary mental events and an interpretation of self-represented futures as extended mental events. ${ }^{2}$ He does not consider the third option, developed in some detail in A future like ours revisited, that self-represented futures are dispositional mental states. ${ }^{3}$ This is surprising, since the vast majority of mental states are dispositional: virtually all of one's factual beliefs, personal memories, skills, and I would argue, hopes are dreams, are realized capacities, not momentary or extended events.

Consider two patients, one an anaesthetised scholar of medieval literature and one a fetus. The scholar has a great many dispositional beliefs about Chaucer because she has the realised capacity to express those beliefs; the fetus has none. The scholar has a great many dispositional hopes and dreams; the fetus has none. Other people may have hopes and dreams on behalf of the fetus; and some of them may be tempted to speak of the fetus as a child, but these are thoughts in the minds of adults, projected onto the fetus. If a child is someone with its own hopes and dreams, then the fetus is not a child. People who envisage a future in which the fetus has become a child generate within themselves powerful emotions of empathetic identification, but this practice should not be permitted to limit the reproductive rights of other people. One must not mistake moral fervour for ethical justification.

\section{REFERENCES}

1 Marquis D. Why abortion is immoral. The Journal of Philosophy 1989;86:183-202.

2 Marquis D. A defence of the potential future of value theory. Journal of Medical Ethics 2002;28:198-201.

3 Brown M. A future like ours revisited. Journal of Medical Ethics 2002;28: 192-5. 